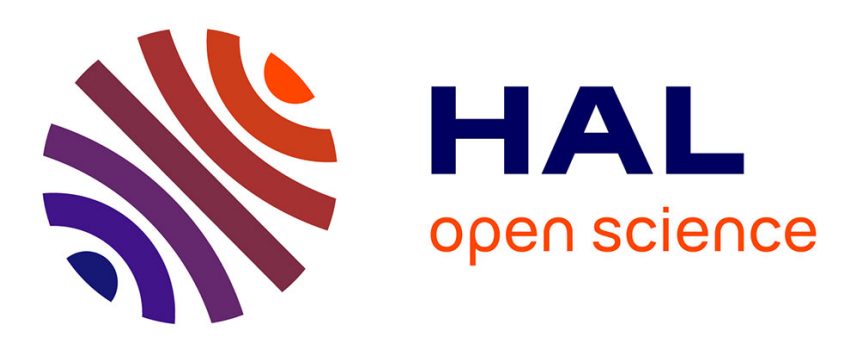

\title{
Reply to 'Letter to the editor: is maximal diaphragm tissue velocity suited for the assessment of diaphragm contractility?'
}

Thomas Poulard, Martin Dres, Marie-Cécile Nierat, Isabelle Rivals, Jean-Yves Hogrel, Thomas Similowski, Jean-Luc Gennisson, Damien Bachasson

\section{To cite this version:}

Thomas Poulard, Martin Dres, Marie-Cécile Nierat, Isabelle Rivals, Jean-Yves Hogrel, et al.. Reply to 'Letter to the editor: is maximal diaphragm tissue velocity suited for the assessment of diaphragm contractility?'. The Journal of Physiology, 2021, 599 (8), pp.2343-2344. 10.1113/JP281433 . hal03366488

\section{HAL Id: hal-03366488 \\ https: / hal.sorbonne-universite.fr/hal-03366488}

Submitted on 5 Oct 2021

HAL is a multi-disciplinary open access archive for the deposit and dissemination of scientific research documents, whether they are published or not. The documents may come from teaching and research institutions in France or abroad, or from public or private research centers.
L'archive ouverte pluridisciplinaire HAL, est destinée au dépôt et à la diffusion de documents scientifiques de niveau recherche, publiés ou non, émanant des établissements d'enseignement et de recherche français ou étrangers, des laboratoires publics ou privés. 
The Journal of Physiology

https://jp.msubmit.net

JP-RL-2021-281433

Title: Reply to "Letter to the editor: Is maximal diaphragm tissue velocity suited for the assessment of diaphragm contractility?"

\author{
Authors: Thomas Poulard \\ Martin Dres \\ Marie-Cécile Nierat \\ Isabelle Rivals \\ Jean-Yves Hogrel \\ Thomas Similowski \\ Jean-Luc Gennisson \\ Damien Bachasson
}

Author Conflict: No competing interests declared

Author Contribution: Thomas Poulard: Conception or design of the work; Acquisition or analysis or interpretation of data for the work; Drafting the work or revising it critically for important intellectual content; Final approval of the version to be published; Agreement to be accountable for all aspects of the work Martin Dres: Conception or design of the work; Acquisition or analysis or interpretation of data for the work; Drafting the work or revising it critically for important intellectual content; Final approval of the version to be published; Agreement to be accountable for all aspects of the work Marie-Cécile Nierat: Conception or design of the work; Acquisition or analysis or interpretation of data for the work; Drafting the work or revising it critically for important intellectual content; Final approval of the version to be published; Agreement to be accountable for all aspects of the work Isabelle Rivals: Conception or design of 
the work; Acquisition or analysis or interpretation of data for the work; Drafting the work or revising it critically for important intellectual content; Final approval of the version to be published; Agreement to be accountable for all aspects of the work JeanYves Hogrel: Conception or design of the work; Acquisition or analysis or interpretation of data for the work; Drafting the work or revising it critically for important intellectual content; Final approval of the version to be published; Agreement to be accountable for

all aspects of the work Thomas Similowski: Conception or design of the work;

Acquisition or analysis or interpretation of data for the work; Drafting the work or revising it critically for important intellectual content; Final approval of the version to be published; Agreement to be accountable for all aspects of the work Jean-Luc Gennisson: Conception or design of the work; Acquisition or analysis or interpretation of data for the work; Drafting the work or revising it critically for important intellectual content;

Final approval of the version to be published; Agreement to be accountable for all aspects of the work Damien Bachasson: Conception or design of the work; Acquisition or analysis or interpretation of data for the work; Drafting the work or revising it critically for important intellectual content; Final approval of the version to be published;

Agreement to be accountable for all aspects of the work

\section{Running Title:}

\section{Dual Publication: N/a}

Funding: Fondation EDF: Thomas Poulard, Jean-Yves Hogrel, Jean-Luc Gennisson, Damien Bachasson, N/A; Association Francaise contre les Myopathies (Association Française contre les Myopathies): Thomas Poulard, Jean-Yves Hogrel, Damien Bachasson, N/A The PhD fellowship of TP is funded by the Fondation EDF that is supporting the RespiMyo project, which includes the current work. This study was also supported by the Association Française Contre Les Myopathies (AFM). 


\section{Reply to "Letter to the editor: Is maximal diaphragm tissue velocity suited for the assessment of diaphragm contractility?"}

Thomas Poulard ${ }^{1,2}$, Martin Dres ${ }^{3,4}$, Marie-Cécile Niérat ${ }^{3}$, Isabelle Rivals ${ }^{5}$, Jean-Yves Hogrel ${ }^{2}$, Thomas Similowski ${ }^{3,4}$, Jean-Luc Gennisson ${ }^{1 \#}$, Damien Bachasson ${ }^{\text {2\#* }}$

\# equally contributing authors

${ }^{1}$ Laboratoire d'Imagerie Biomédicale Multimodale, BioMaps, Université Paris-Saclay, CEA, CNRS UMR 9011, Inserm UMR1281, SHFJ, 4 place du général Leclerc, 91401, Orsay, France

2 Institute of Myology, Neuromuscular Investigation Center, Neuromuscular Physiology Laboratory, Paris, France

${ }^{3}$ Sorbonne Université, INSERM, UMRS1158 Neurophysiologie respiratoire expérimentale et clinique, Paris, France

${ }^{4}$ AP-HP. Sorbonne Université, Hôpital Pitié-Salpêtrière, Service de Pneumologie, Médecine intensive - Réanimation (Département "R3S"), F-75013, Paris, France

${ }^{5}$ Equipe de Statistique Appliquée, ESPCI Paris, PSL Research University, UMRS 1158, 10 rue Vauquelin, 75005, Paris, France

*Corresponding author: Damien Bachasson, PhD. Institut de Myologie, Laboratoire de Physiologie et d'Evaluation Neuromusculaire, Hôpital Universitaire Pitié Salpêtrière, Paris 75651 Cedex 13, France. Tel: +33 1421666 41; fax: +33 1421658 81. E-mail: d.bachasson@institutmyologie.org 
To the Editor: We appreciate the opportunity given by the Editor to respond to Dr. Beltrami's Letter regarding our recent publication (Poulard et al., 2020) in the Journal of Physiology. Below, we have paraphrased the main criticisms, each followed by our response.

Dr. Beltrami questioned the design of our study:

"Participants underwent a single trial, where a minimum of 3 stimulations were performed at every intensity, and 2 to 3 of these were used for subsequent analysis. In our opinion this does not constitute an adequate setting to evaluate inter-session reliability"

One must note that inter-session reliability was not assessed in the current work. However, we assessed intra-session reliability of $\mathrm{P}_{\mathrm{di}, \mathrm{tw}}, \mathrm{V}_{\mathrm{di}, \max }$, and $\mathrm{TF}_{\mathrm{di}, \text { tw }}$ by comparing values obtained at any given stimulation intensity. As clearly mentioned in the Discussion: "between-day reliability of $V_{d i, \max }$ remains to be investigated". A different design will be chosen to investigate this question.

Dr. Beltrami expresses concerns regarding the interpretation we made of standard error of measurements (SEM):

"In our opinion the authors misinterpreted the message given by their standard error of measurement (SEM) [...] the relative SEM for $V_{d i, \max }$ is 2.5 bigger than that of Pditw $[\ldots]$ the ICC of both measures are also not comparable, as that of $V_{d i, \max }(0.86,95 \%$ CI 0.81; 0.90) is clearly outside the boundaries of that for $P_{d i, t w}\left(95 \%\right.$ CI 0.96; 0.98) [...] SEM for TF $F_{d i, t w}$ was not $10 \%$ but rather $\sim 50 \%$ if expressed in relative terms"

As previously discussed with Dr Beltrami in several email exchanges, the message we tried to convey was that SEM and ICC for $\mathrm{V}_{\mathrm{di}, \max }$ appeared to be acceptable, and importantly, much more reliable than $\mathrm{TF}_{\mathrm{di}, \mathrm{tw}}$. It must also be noted that one must be careful when inferring SEM values expressed as a percentage from SEM and average values. To achieve this, analysis of logtransformed variables is required to estimate errors when the standard deviations expressed as percentages (coefficients of variation) apply more accurately to a full population given the between-individual variability (Hopkins, 2000). Moreover, one should not lose sight of the fact that these analyses involve all responses at all intensities and are likely to be less reliable than what can be expected when considering supramaximal stimulation only. ICC for $\mathrm{V}_{\mathrm{di} \text {,max }}$ was > 0.85, which can be considered high enough to be considered as a reproducible index ( $\mathrm{Koo} \& \mathrm{Li}$, 2016). Dr Beltrami's statement regarding the $\mathrm{SEM}$ of $\mathrm{TF}_{\mathrm{di}, \mathrm{tw}}$ is also incorrect as percentage and 
percentage points were not confused. All SEM values were presented in the corresponding unit for each variable (i.e. $\mathrm{cmH}_{2} \mathrm{O}$ for $\mathrm{P}_{\mathrm{di}, \mathrm{tw}}, \mathrm{mm}^{-1} \mathrm{~s}^{-1}$ for $\mathrm{V}_{\mathrm{di} \text {,max }}$, and $\%$ for $\mathrm{TF}_{\mathrm{di}, \mathrm{tw}}$ ). Although the ICC for $\mathrm{V}_{\mathrm{di} \text {,max }}$ was outside the $95 \%$ confidence interval of that for $\mathrm{P}_{\mathrm{di}, \mathrm{tw}}$, the ICC was $>0.85$ which supports $\mathrm{V}_{\mathrm{di}, \max }$ as a reproducible index when it comes to relative reliability (Koo \& Li, 2016).

Dr. Beltrami also writes the following:

" $P_{\text {di,tw }}$ values are typically only used from supra-maximal stimulation, so although it is interesting that there was a correlation between the two variables when low stimulation intensities are considered, it is unclear from the data whether there is a relationship between $P_{d i, t w}$ and $V_{d i, \text { max. }}$,

In the current work, change in cervical magnetic stimulation intensity was used as an experimental paradigm for eliciting various levels of $\mathrm{P}_{\mathrm{di}, \mathrm{tw}}$. Therefore, obtaining supramaximal $\mathrm{P}_{\mathrm{di}, \mathrm{tw}}$ was not essential for our work. We used a broad range of cervical magnetic stimulation intensities to investigate the sensitivity of indices derived from ultrafast ultrasound imaging to changes in diaphragm contraction levels. Within our publication, Figure 7.A clearly illustrates the relationship between $\mathrm{P}_{\mathrm{di}, \mathrm{tw}}$ and $\mathrm{V}_{\mathrm{di} \text {,max }}$. In the text, we clearly state that a significant relationship was found between $\mathrm{P}_{\mathrm{di}, \mathrm{tw}}$ and $\mathrm{V}_{\mathrm{di} \text {,max }}$ within all participants $(\rho=0.64-1.00$, all $\mathrm{p}<0.05)$ as well as at the group level, as assessed using repeated measures correlation coefficient $(\mathrm{R}=0.75(95 \% \mathrm{CI}$ : $0.65,0.83), \mathrm{p}<0.0001)$.

Dr Beltrami also stated:

"We recalculated the data from Poulard, and found no relationship between $P_{\text {di,tw }}$ and $V_{\text {di,max }}\left(R^{2}\right.$ $=0.01, F(1,11)=0.157, P=0.699) ”$

Dr. Beltrami did not find the same results as we did because he did not perform the same analysis as us (although it remains unclear which exact analysis Dr Beltrami performed, since we found a coefficient of determination of 0.39 when considering all data points sent to Dr. Beltrami). In the publication, we did not calculate a coefficient of determination $\left(\mathrm{R}^{2}\right)$ but a repeated measure correlation coefficient (R) (Bakdash \& Marusich, 2017). As mentioned in the Statistical Analysis section of our paper, this technique "considers the independence of repeated measures between individuals, so that potential confounding factors, such as between-participant variability, do not interfere”. 
Dr. Beltrami also raises some concerns about the fact that $\mathrm{V}_{\mathrm{di}, \mathrm{max}}$ may be independent of $\mathrm{P}_{\mathrm{di}, \mathrm{tw}}$, because several participants reached supramaximality for $\mathrm{P}_{\mathrm{di}, \mathrm{tw}}$ and not for $\mathrm{V}_{\mathrm{di}, \mathrm{max}}$, or vice-versa. The key concept behind this part of the Discussion is that the recruitment of accessory inspiratory muscles may also contribute to $\mathrm{Pdi}_{\mathrm{tw}}$, particularly at high stimulation intensities (Wragg et al., 1994; Laghi et al., 1996; Attali et al., 1997). In some participants, $\mathrm{V}_{\mathrm{di}, \max }$ reached a plateau at $\sim 90$ $\%$ of maximal stimulation intensity while $\mathrm{Pdi}_{\mathrm{tw}}$ increased up to $100 \%$. Because we hypothesized $\mathrm{V}_{\mathrm{di}, \max }$ to be highly specific of diaphragm contraction and, unlike $\mathrm{P}_{\mathrm{di}, \mathrm{tw}}$, potentially unaffected by the recruitment of neck inspiratory muscles, we suggested that $\mathrm{V}_{\mathrm{di} \text {,max }}$ may be an interesting index to detect supramaximality of evoked diaphragm contraction.

Dr. Beltrami concludes with the following statement:

"While $V_{\text {di,max }}$ might prove itself better at identifying contractility/weakness of the diaphragm, in our opinion inferences in this direction cannot be made from the available data."

We believe that Dr Beltrami's concerns regarding the potential power of Vdi,max for the detection of diaphragm dysfunction is beyond the scope of this paper of which we must recall the main objective: capturing a 300-ms lasting evoked contraction of the diaphragm using ultrafast ultrasound and investigating potential relationships between metrics derived from ultrafast ultrasound with the reference method i.e. Pdi,tw. Accordingly, we can only concur with this statement, as it was never an objective of the current work to determine if $\mathrm{V}_{\mathrm{di} \text {,max }}$ could identify diaphragm weakness as the participants recruited were all healthy and with normal respiratory function. For these reasons, we explicitly stated that "Further studies will focus on this specific point (i.e. $\mathrm{V}_{\mathrm{di}, \max }$ ability to determine diaphragm dysfunction), with the perspective that $V_{\text {di,max }}$ may be one parameter, among others, guiding clinicians through the assessment of diaphragm contractility". We are currently investigating the diagnostic power of our approach in patients with suspicion of diaphragm dysfunction. In due time, we will be pleased to share our findings with the scientific community.

\section{Additional information}

\section{Competing interests}


None.

\section{Fundings}

The $\mathrm{PhD}$ fellowship of TP is funded by the Fondation EDF that is supporting the RespiMyo project, which includes the current work. This study was also supported by the Association Française Contre Les Myopathies (AFM).

\section{Author contributions}

All persons designated as authors qualify for authorship, and all those who qualify for authorship are listed.

\section{References}

Attali V, Mehiri S, Straus C, Salachas F, Arnulf I, Meininger V, Derenne JP \& Similowski T. (1997). Influence of neck muscles on mouth pressure response to cervical magnetic stimulation. Am J Respir Crit Care Med 156, 509-514.

Bakdash JZ \& Marusich LR. (2017). Repeated Measures Correlation. Front Psychol 8, 456.

Hopkins WG. (2000). Measures of reliability in sports medicine and science. Sports Med 30, 115.

Koo TK \& Li MY. (2016). A Guideline of Selecting and Reporting Intraclass Correlation Coefficients for Reliability Research. J Chiropr Med 15, 155-163.

Laghi F, Harrison MJ \& Tobin MJ. (1996). Comparison of magnetic and electrical phrenic nerve stimulation in assessment of diaphragmatic contractility. J Appl Physiol (1985) 80, 17311742. 
Poulard T, Dres M, Niérat MC, Rivals I, Hogrel JY, Similowski T, Gennisson JL \& Bachasson D. (2020). Ultrafast ultrasound coupled with cervical magnetic stimulation for noninvasive and non-volitional assessment of diaphragm contractility. $J$ Physiol.

Wragg S, Aquilina R, Moran J, Ridding M, Hamnegard C, Fearn T, Green M \& Moxham J. (1994). Comparison of cervical magnetic stimulation and bilateral percutaneous electrical stimulation of the phrenic nerves in normal subjects. Eur Respir J 7, 1788-1792. 